\title{
Elisabeth DE BRUIJN, The Southern Appeal: Dutch Translations of French Romances (c. 1484-c. 1540) in a Western European Perspective
}

\section{Maria Colombo Timelli}

\section{(2) OpenEdition}

\section{Journals}

\section{Édition électronique}

URL : https://journals.openedition.org/studifrancesi/44480

DOI : 10.4000/studifrancesi.44480

ISSN : 2421-5856

Éditeur

Rosenberg \& Sellier

\section{Édition imprimée}

Date de publication : 1 juin 2021

Pagination : 197

ISSN : 0039-2944

\section{Référence électronique}

Maria Colombo Timelli, «Elisabeth DE BRUIJN, The Southern Appeal: Dutch Translations of French

Romances (c. 1484-c. 1540) in a Western European Perspective », Studi Francesi [En ligne], 193 (LXV | I) |

2021, mis en ligne le 01 juillet 2021, consulté le 15 octobre 2022. URL : http://

journals.openedition.org/studifrancesi/44480 ; DOI : https://doi.org/10.4000/studifrancesi.44480

Ce document a été généré automatiquement le 15 octobre 2022.

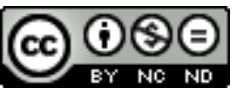

Creative Commons - Attribution - Pas d'Utilisation Commerciale - Pas de Modification 4.0 International - CC BY-NC-ND 4.0

https://creativecommons.org/licenses/by-nc-nd/4.0/ 


\title{
Elisabeth DE BRUIJN, The Southern Appeal: Dutch Translations of French Romances (c. 1484-c. 1540) in a Western European Perspective
}

\author{
Maria Colombo Timelli
}

\section{RÉFÉRENCE}

Elisabeth DE BRUIJN, The Southern Appeal: Dutch Translations of French Romances (c. 1484-c. 1540) in a Western European Perspective, pp. 93-124.

L'intérêt de cet article repose tant sur le corpus des romans français traduits en néerlandais et publiés dans les Pays-Bas méridionaux entre 1484 et les années 1540, que dans le traitement que leur réservèrent les éditeurs impliqués dans cette diffusion. Les titres concernés correspondent pour la quasi-totalité à des romans en prose du $\mathrm{XV}^{\mathrm{e}}$ siècle: Jason, Recueil des Histoires de Troyes, Esope de Julien Macho, Paris et Vienne, Mélusine de Jean d'Arras, Roman de Troyle, Beuve de Hantone, Hercule, Olivier de Castille, Robert le Diable, Destruction de Jérusalem, Pierre de Provence, Galien Rethoré; pour la plupart, des œuvres qui ont connu un long succès dans leur langue originale. Tout en s'appuyant sur des titres «sûrs», les éditeurs néerlandais n'hésitèrent pas à les adapter à leurs propres lecteurs, entre autres en les abrégeant, parfois en compilant des sources diverses, mais surtout en enchâssant des passages en vers; la suppression des noms des personnages historiques évoqués dans les prologues d'origine - auteurs ou dédicataires - correspond sans doute aussi au changement de public, plus aristocratique en France, urbain dans les grandes villes des Pays-Bas. On retiendra enfin une nette baisse d'intérêt pour cette production à partir des années 1520-1530, décennie charnière également en France. 